SOUZA, Rubin Assis da Silveira. A irrelevância do conceito de soberania para Hans Kelsen. Revista Eletrônica Direito e Política, Programa de Pós-Graduação Stricto Sensu em Ciência Jurídica da UNIVALI, Itajaí, v.11, n.2, 2ㅇ quadrimestre de 2016. Disponível em: www.univali.br/direitoepolitica - ISSN 1980-7791.

\title{
A IRRELEVÂNCIA DO CONCEITO DE SOBERANIA PARA HANS KELSEN
}

THE IRRELEVANCE OF THE CONCEPT OF SOVEREIGNTY FOR HANS KELSEN

\section{Rubin Assis da Silveira Souza ${ }^{1}$}

SUMÁRIO: Introdução. 1. Quem, de fato, é o soberano?; 2. Dualismo e monismo entre direito nacional e internacional; 2.10 primado do direito nacional; 2.20 primado do direito internacional; 3 A escolha de um ou outro primado a partir da concepção de vida - a irrelevância constitucional e jurídica do conceito de soberania; Considerações finais; Referências das fontes citadas

\section{RESUMO}

O presente artigo aborda o problema da soberania para Hans Kelsen. Tem como objetivo analisar a posição do autor sobre o tema (especialmente através do texto Sovereignty), traçando paralelamente algumas considerações. Ocorre que para Kelsen o conceito de soberania mostra-se impreciso a partir da doutrina tradicional. Ainda, mesmo superando essa doutrina e a teoria dualista, também o conteúdo do direito nacional e internacional permanece inalterado. Portanto, prova-se a irrelevância de tal para a teoria jurídica.

PALAVRAS-CHAVES: Soberania; monismo; dualismo; direito internacional; direito nacional.

\section{ABSTRACT}

This paper deals with the problem of sovereignty in Hans Kelsen. Analyzes the author's position about the theme (especially through the text Soverignty) and traces some considerations in parallel. According to Kelsen, the traditional concept of sovereignty is inaccurate. Surpassing this traditional doctrine and the dualistic

\footnotetext{
${ }^{1}$ Graduado em direito e filosofia e mestre em filosofia pela Universidade Federal de Pelotas/RS. Mestre em direito e doutorando em filosofia pela Universidade Federal de Santa Catarina/SC. Bolsista CAPES/SC. Florianópolis/SC. E-mail: rubinassissouza@yahoo.com.br.
} 
SOUZA, Rubin Assis da Silveira. A irrelevância do conceito de soberania para Hans Kelsen. Revista Eletrônica Direito e Política, Programa de Pós-Graduação Stricto Sensu em Ciência Jurídica da UNIVALI, Itajaí, v.11, n.2, 2ㅇ quadrimestre de 2016. Disponível em: www.univali.br/direitoepolitica - ISSN 1980-7791.

theory through the monistic theory, also the tenor of national or international law remains unchanged. Therefore, proves the irrelevance of this concept.

KEYWORDS: Sovereignty; monismo; dualism; international law; national law.

\section{INTRODUÇÃO}

O artigo trata do conceito de soberania para Hans Kelsen. Defende que para o jusfilósofo o conceito não interfere no conteúdo do direito tanto nacional quanto internacional e nem na determinação da ciência pura do direito. Portanto, sustenta a hipótese da irrelevância jurídica do problema. Metodologicamente parte-se do texto do autor (Sovereignty) traçando paralelamente alguns comentários e análises sobre o mesmo.

Essa abordagem kelseniana da soberania mostra-se ainda significativa para academia hodiernamente, considerando que continua cara para a doutrina jurídica e filosófica a determinação do Estado soberano. Kelsen, nesse sentido, como se verá no trabalho que se segue, posiciona-se de forma original em relação à teoria tradicional da soberania - procura superá-la, especialmente a teoria tradicional cristã, a qual sustenta a concepção de soberania atrelada à sua moralidade. Também, nesse ínterim, contesta a posição dualista entre direito nacional e internacional.

Nesse sentido, observamos em Kelsen tão somente a viabilidade do conceito de soberania através da concepção monista entre direito estatal e direito internacional. Essa concepção monista, por sua vez, divide-se entre o monismo do primado do direito estatal versus o monismo do primado do direito internacional. Ocorre, entretanto, que 
SOUZA, Rubin Assis da Silveira. A irrelevância do conceito de soberania para Hans Kelsen. Revista Eletrônica Direito e Política, Programa de Pós-Graduação Stricto Sensu em Ciência Jurídica da UNIVALI, Itajaí, v.11, n.2, 2ㅇ quadrimestre de 2016. Disponível em: www.univali.br/direitoepolitica - ISSN 1980-7791.

mesmo sendo viável um conceito de soberania para ambos os primados, em termos jurídicos e constitucionais as normas tanto do direito estatal quanto do direito internacional permanecem inalteradas a partir da posição que se adote. Portanto, conclui-se a irrelevância do problema da soberania.

\section{QUEM, DE FATO, É O SOBERANO?}

A primeira tese refutada por Kelsen acerca da relevância jurídica e constitucional do conceito de soberania corresponde à ideia do Estado soberano ou de um sujeito soberano acima do sistema normativo. ${ }^{2}$

Nesse sentido, Kelsen ${ }^{3}$ ressalta a imprecisão do termo 'soberania', assim como contesta a coerência da teoria tradicional. ${ }^{4}$ Ocorre que geralmente o significado do termo consiste na determinação do Estado nacional como detentor do supremo poder de controle do comportamento humano. ${ }^{5} \mathrm{O}$ problema, contudo, incide a partir da impossibilidade de vinculação desse Estado, caso efetivamente a teoria tradicional fosse coerente, a qualquer critério que the determine, isto é, não pode haver qualquer conceito de soberano, pois tal situação atrelaria o próprio ao seu conceito. Por exemplo, se vincularmos o Estado soberano à legitimidade do povo para o efetivo exercício do seu poder supremo, o soberano em si mesmo seria o conceito vinculante de povo, e não mais a autoridade maior do

2 KELSEN, Hans. Sovereignty. In: PAULSON, Bonnie Litschewski e PAULSON, Stanley (Orgs.). Normativity and Norms: Critical Perspectives on Kelsenian Themes. New York: Oxford University Press Inc.: 2007, p. 525.

3 KELSEN, Hans. Sovereignty. p. 525, §10, linha 1.

4 Kelsen, na passagem em questão, não especifica o defensor dessa 'teoria tradicional', apenas a cita de forma genérica. Relevante conferir, porém, o juízo sobre a tese de Umberto Campagnolo, no qual Kelsen expressamente se opõe a tese de seu aluno, que conceituava a soberania como "autoridade absoluta em relação aos seus sujeitos". In: KELSEN, Hans. Direito internacional e Estado soberano. Tradução de Marcela Varejão. São Paulo: Martins Fontes, 2002, p. 121 ss.

${ }^{5}$ KELSEN, Hans. Sovereignty. p. 525, §10, linha 4. 
SOUZA, Rubin Assis da Silveira. A irrelevância do conceito de soberania para Hans Kelsen. Revista Eletrônica Direito e Política, Programa de Pós-Graduação Stricto Sensu em Ciência Jurídica da UNIVALI, Itajaí, v.11, n.2, 2ㅇ quadrimestre de 2016. Disponível em: www.univali.br/direitoepolitica - ISSN 1980-7791.

Estado. Ou ainda, se determinássemos o soberano como aquele de decide no estado de exceção, esse estado de exceção é quem o definiria, tornando o conceito também incoerente. Por corolário, se vinculássemos ao conceito de soberania qualquer outra condição, seja empírica ou racional, essa condição seria, efetivamente, o poder maior do Estado.

Há de se perceber, ainda, que o problema agrava-se tendo em vista a necessidade de definir o conceito de soberano para reivindicar a ideia do Estado soberano. Do contrário, não haveria qualquer especificação de soberania. Destarte, a distinção consiste na necessária construção de um conceito objetivo. Contudo, é ilógico admitir um conceito determinante sem transferir para outro nível o efetivo poder do Estado. Portanto, a teoria tradicional não se sustenta pelo viés epistemológico. ${ }^{6}$

A teoria tradicional, porém, ampara-se sobre a vinculação da validade da vontade soberana à legitimidade moral. Para Kelsen7, a doutrina cristã representa essa tentativa de dar poder supremo a alguém

\footnotetext{
${ }^{6}$ Aqui identificamos a influência neokantiana em Kelsen. O conhecimento, para o autor, não espelha uma realidade dada, mas também determina o objeto e, tão logo, o cria. Afirma: "Também é verdade que, no sentido da teoria do conhecimento de Kant, a ciência jurídica como conhecimento do Direito, assim como todo o conhecimento, tem caráter constitutivo e, por conseguinte, "produz" o seu objeto na medida em que o apreende como um todo com sentido. Assim como o caos das sensações só através do conhecimento ordenador da ciência se transforma em cosmos, isto é, em natureza como um sistema unitário, assim também a pluralidade das normas jurídicas gerais e individuais postas pelos órgãos jurídicos, isto é, o material dado à ciência do Direito, só através do conhecimento da ciência jurídica se transforma num sistema unitário isento de contradições, ou seja, numa ordem jurídica." KELSEN, Hans. Teoria pura do direito. Tradução de João Baptistas Machado. 8. ed. São Paulo: Editora WMF Martins Fontes, 2009, p. 81 e 82. Consequentemente, todo conceito de soberano também determina o próprio soberano, tornando-o contraditório.

7 KELSEN, Hans. Sovereignty. p. 525, §10, linha 13.
} 
SOUZA, Rubin Assis da Silveira. A irrelevância do conceito de soberania para Hans Kelsen. Revista Eletrônica Direito e Política, Programa de Pós-Graduação Stricto Sensu em Ciência Jurídica da UNIVALI, Itajaí, v.11, n.2, 2ㅇ quadrimestre de 2016. Disponível em: www.univali.br/direitoepolitica - ISSN 1980-7791.

limitando e determinando esse poder à sua autoridade moral. ${ }^{8}$ De tal modo, a teoria tradicional cristã atrela a validade do Estado à sua moralidade e ao mesmo tempo (o que torna ambíguo o conceito) procura preservar o Estado soberano como a autoridade maior e como um poder que não está submetido a nenhuma outra ordem legal superior. Aqui reside um dualismo contraditório - ora, se o soberano detém o poder supremo, de forma alguma poderia estar limitado por qualquer tipo de moralidade.

Opondo-se a essa teoria, Kelsen ${ }^{9}$ assevera que a soberania corresponde somente ao Estado enquanto sistema legal (e não acima do sistema normativo), isto é, um sistema que regula o comportamento humano. Ou seja, não há como determinar qualquer soberano que não o próprio sistema normativo, o qual obtém validade objetiva tão somente através da pressuposição lógicofundamental de uma norma superior. ${ }^{10}$ Nesse caso, a pergunta possível não é mais: quem é o soberano? Porém, qual o sistema normativo é o soberano? Não se questiona quem é o sujeito soberano, mas qual sistema normativo vale, isto é, obrigatório para todos e não determinado por outro sistema jurídico superior. A teoria da soberania a partir daí foca nos dois tipos de sistema normativos

8 Novamente nesse ponto Kelsen aponta para uma teoria genérica, não especificando qual doutrina tradicional cristã defende essa tese. Especula-se, como o faz VIANELLO, Lorenzo Cordova. Derecho y poder: Kelsen y Schmitt frente a frente. Mexico: Fondo de Cultura Económica, 2010. Edição Kindle., Capítulo V. La primacía del poder sobre el derecho: la concepción schmittiana del derecho. Seção 4. El decisionismo y la soberania), que tal teoria da soberania kelseniana destina-se contra a teologia política de Carl Schmitt. Entretanto, não há referência expressa de Kelsen a Schmitt no texto em análise.

Nessa mesma linha comparativa, conferir DYZENHAUS, David. Kelsen, Heller and Schmitt: Paradigms of Sovereignty Thought. Theoretical Inquiries in Law. Vol 16, n. 2, 2015, p. 337-366.

${ }^{9}$ KELSEN, Hans. Sovereignty. p. 526, in fine.

10 Sobre a validade do sistema normativo, conferir a própria Teoria pura, in: KELSEN, Teoria pura do direito. p. 221. 
SOUZA, Rubin Assis da Silveira. A irrelevância do conceito de soberania para Hans Kelsen. Revista Eletrônica Direito e Política, Programa de Pós-Graduação Stricto Sensu em Ciência Jurídica da UNIVALI, Itajaí, v.11, n.2, 2ㅇ quadrimestre de 2016. Disponível em: www.univali.br/direitoepolitica - ISSN 1980-7791.

existentes - o sistema normativo estatal ou o sistema normativo internacional. O problema, em suma, corresponde somente ao Estado enquanto sistema legal (e não como poder supremo sobre o comportamento humano) e a prevalência da ordem jurídica interna e externa marca a posição política de cada normatividade.

\section{DUALISMO E MONISMO ENTRE DIREITO NACIONAL E INTERNACIONAL}

Para Kelsen ${ }^{11}$, superadas a doutrina tradicional e tradicional cristã, restam duas teorias adversárias acerca do problema da relação entre os sistemas de direito estatal e internacional - o dualismo (ou pluralismo) versus o monismo. De acordo com o dualismo, o direito estatal e internacional são dois sistemas normativos independentes um do outro e válidos ao mesmo tempo. Conforme o dualismo, um comportamento humano pode ser julgado tanto pelo ponto de vista do direito nacional quanto internacional. Ao contrário, a teoria monista entende que os dois sistemas normativos formam uma unidade, que por sua vez admite tanto o primado do direito nacional quanto o primado do direito internacional.

Sucede, segundo Kelsen ${ }^{12}$, que se alguém reconhece a imposição de obrigações sobre o Estado pelo direito internacional, isto é, a possibilidade do direito internacional delegar poder para o sistema jurídico estatal especificar deveres, então o sistema dualista entra em colapso. ${ }^{13}$ Isso porque o dualismo não pode aceitar o sistema

\footnotetext{
${ }^{11}$ KELSEN, Hans. Sovereignty. p. 526 e 527.

12 KELSEN, Hans. Sovereignty. p. 527.

13 Sobre a impossibilidade do sistema dualista ou pluralista, conferir a crítica a Kelsen de H.L.A. Hart sobre o problema da norma fundamental e as normas de reconhecimento do Estado e do direito internacional. In: HART, H.L.A. Kelsen's Doctrine of the Unity of Law. In: PAULSON, Bonnie Litschewski e PAULSON, Stanley (Orgs.). Normativity and Norms: Critical Perspectives on Kelsenian Themes. New
} 
SOUZA, Rubin Assis da Silveira. A irrelevância do conceito de soberania para Hans Kelsen. Revista Eletrônica Direito e Política, Programa de Pós-Graduação Stricto Sensu em Ciência Jurídica da UNIVALI, Itajaí, v.11, n.2, 2ㅇ quadrimestre de 2016. Disponível em: www.univali.br/direitoepolitica - ISSN 1980-7791.

normativo internacional como válido internamente. Quando o faz, resulta em contradição. A unidade dos sistemas, representada pela teoria monista, não tem essa preocupação. Ela pode explicar a relação entre o direito estatal e internacional sem tal contradição, na qual recai necessariamente a teoria dualista. A teoria monista também pode mostrar que, pelo princípio da efetividade, o direito positivo internacional determina a base e a esfera da validade do sistema legal estatal, a qual torna indubitável a unidade epistêmica entre o direito internacional e o direito do Estado. ${ }^{14}$

Diz o autor em outra importante obra sobre o mesmo tema15:

Esse dualismo ou - levando em conta a existência de numerosas ordens jurídicas nacionais - esse pluralismo contradiz, conforme vimos, o conteúdo do Direito Internacional, pois ele próprio estabelece uma relação entre suas normas e as das diferentes ordens jurídicas nacionais. A teoria pluralista está em contradição com o Direito Positivo, na medida em que o Direito Internacional seja considerado uma ordem jurídica válida. $\mathrm{E}$ os próprios representantes dessa teoria aceitam o Direito Internacional como Direito Positivo.

A percepção pluralista também não se sustenta no campo lógico. O Direito internacional e o Direito Nacional não podem ser sistemas jurídicos distintos e mutuamente independentes se as normas forem consideradas válidas para o mesmo espaço e ao mesmo tempo. É impossível logicamente supor que as normas simultaneamente válidas pertençam a sistemas diferentes, mutualmente independentes.

York: Oxford University Press Inc.: 2007, p. 578. Também conferir STARKE, Joseph G. Monism and Dualism in the Theory of International Law. In: PAULSON, Bonnie Litschewski e PAULSON, Stanley (Orgs.). Normativity and Norms: Critical Perspectives on Kelsenian Themes. New York: Oxford University Press Inc.: 2007, p. 537, sobre a origem kelseniana da refutação da teoria dualista e a afirmação do monismo.

14 Interessante observar a forma irônica com que Kelsen aborda o problema na Teoria pura do direito. Diz o autor, citando São Mateus, VI, 23: "Ninguém pode obedecer a dois senhores". KELSEN, Hans, Teoria pura do direito. p. 365.

15 KELSEN, Hans. Princípios do direito internacional. Tradução de Ulrich Dressel e Gilmar Antonio Bedin. Ijuí: Editora Unijuí, 2010. 
SOUZA, Rubin Assis da Silveira. A irrelevância do conceito de soberania para Hans Kelsen. Revista Eletrônica Direito e Política, Programa de Pós-Graduação Stricto Sensu em Ciência Jurídica da UNIVALI, Itajaí, v.11, n.2, 2ㅇ quadrimestre de 2016. Disponível em: www.univali.br/direitoepolitica - ISSN 1980-7791.

Os pluralistas não negam que as normas de Direito Internacional e as do Direito Nacional sejam simultaneamente válidas. Pelo contrário, pressupondo que ambas sejam válidas simultaneamente, eles defendem que prevalece uma determinada relação entre as duas, a saber, a relação de independência mútua, o que significa que não existe relação entre os dois sistemas de normas válidas. Isso é, contudo, como veremos, uma verdadeira contradição lógica.

Enfim, Kelsen também refuta, além das teorias tradicionais, a teoria dualista do direito nacional e internacional. Para os dualistas, o sistema jurídico estatal seria o soberano, ao mesmo tempo em que o direito internacional também teria normas válidas e independentes do direito nacional. Ora, há, aqui, um conflito irresolúvel entre sistemas, o que torna impossível a concepção dualista de soberania.

Superado o dualismo, resta apenas a descrição do monismo e suas subdivisões em monismo do primado do direito nacional versus o monismo do primado do direito internacional. Cabe também ressaltar que o monismo não significa a ratificação de uma Constituição do direito internacional sobre o direito nacional. Esse caso só seria viável na hipótese de um Estado mundial, no qual o monopólio da força legítima se deslocaria das nações para a concentração em um órgão superior mundial, com a pressuposição de apenas uma norma fundamental para todos os Estados. Segundo Kelsen ${ }^{16}$, essa não é uma opção verificável na sua conjuntura política. Ao contrário, o direito internacional permanece tal qual as tribos primitivas, nas quais há um direito, porém sem um Estado. ${ }^{17}$ Conforme o autor ${ }^{18}$ :

\footnotetext{
${ }^{16}$ KELSEN, Hans. Teoria pura do direito. p. 364.

17 Conferir sobre as sociedades primitivas e a existência de um direito sem Estado na obra Sociedad y naturaleza in: KELSEN, Hans. Sociedad y Naturaleza: una investigacion sociologica. Tradução: Jaime Perriaux. Buenos Aires: Editorial DEPALMA, 1945.

${ }^{18}$ Kelsen, Hans. Teoria pura do direito. p. 358 e 364
} 
SOUZA, Rubin Assis da Silveira. A irrelevância do conceito de soberania para Hans Kelsen. Revista Eletrônica Direito e Política, Programa de Pós-Graduação Stricto Sensu em Ciência Jurídica da UNIVALI, Itajaí, v.11, n.2, 2ㅇ quadrimestre de 2016. Disponível em: www.univali.br/direitoepolitica - ISSN 1980-7791.

O Direito internacional, como ordem coerciva, mostra, na verdade, o mesmo caráter que o Direito estadual. Distingue-se dele, porém, e revela uma certa semelhança com o Direito da sociedade primitiva, pelo fato de não instituir, pelo menos enquanto Direito internacional geral vinculante em relação a todos os Estados, quaisquer órgãos funcionando segundo 0 princípio da divisão do trabalho para a criação e aplicação das suas normas. Encontra-se ainda num estádio de grande descentralização.

(...)

Toda a evolução técnico-jurídica apontada tem, em última análise, a tendência para fazer desaparecer a linha divisória entre Direito internacional e ordem jurídica do Estado singular. Por forma que o último termo da real evolução jurídica, dirigida a uma centralização cada vez maior, parece ser a unidade de organização de uma comunidade universal de Direito mundial, quer dizer, a formação de um Estado mundial. Presentemente, no entanto, ainda não se pode falar de uma tal comunidade. Apenas existe uma unidade cognoscitiva de todo o Direito, o que significa que podemos conceber o conjunto formado pelo Direito internacional e as ordens jurídicas nacionais como um sistema unitário de normas - justamente como estamos acostumados a considerar como uma unidade a ordem jurídica do Estado singular.

Em suma, a teoria monista não apoia a ideia da pressuposição da norma fundamental acima da Constituição do Estado (como na hipótese de um Estado mundial), mas tão somente o monismo entre a legislação nacional e internacional, cujo primado (mas não o conteúdo) varia conforme as teorias adotadas - a teoria do reconhecimento versus a teoria da efetividade. Ainda, a solução do problema da soberania só pode ser compreendida através da construção monista da relação entre direito internacional e nacional e a diferença entre as duas teorias monistas reside, por sua vez, tão somente na oposição de dois diferentes pontos de vista.

\subsection{O PRIMADO DO DIREITO NACIONAL}


SOUZA, Rubin Assis da Silveira. A irrelevância do conceito de soberania para Hans Kelsen. Revista Eletrônica Direito e Política, Programa de Pós-Graduação Stricto Sensu em Ciência Jurídica da UNIVALI, Itajaí, v.11, n.2, 2ㅇ quadrimestre de 2016. Disponível em: www.univali.br/direitoepolitica - ISSN 1980-7791.

Para Kelsen ${ }^{19}$, partindo-se da primeira construção monista (isto é, o primado do direito nacional), a questão se dá sobre o estabelecimento da validade do direito internacional, visto a validade do direito estatal já estar assegurada. Tal hipótese fundamenta o direito internacional ancorado ao direito estatal, isto é, o direito internacional é válido tão somente se reconhecido pelo sistema jurídico nacional. Esta é a teoria do reconhecimento, para a qual as normas internacionais dependem do reconhecimento do Estado signatário. Segundo Kelsen ${ }^{20}$, essa é a teoria prevalente no direito anglo-americano e expressa nas modernas constituições. ${ }^{21}$ Desse modo, as normas internacionais são compreendidas como um componente do sistema jurídico interno e a base da sua validade encontra-se na Constituição nacional, a qual, por sua vez, é o ponto de partida para a construção da relação entre os dois sistemas. Essa construção é caracterizada pela teoria jurídica como a soberania do Estado. Ou seja, o Estado é soberano se seu sistema jurídico não possui nenhuma norma superior que não a da própria Constituição e as normas externas são válidas se reconhecidas, do contrário não são nem existentes para o sistema jurídico estatal.

Ocorre que, afirma Kelsen ${ }^{22}$, como consequência dessa superioridade do direito nacional e a formação de pactos internacionais, aceita-se o reconhecimento da soberania dos outros Estados em igualdade soberana, isto é, todos são igualmente soberanos e possuem

\footnotetext{
${ }^{19}$ KELSEN, Hans. Sovereignty. p. 528.

20 KELSEN, Hans. Sovereignty. p. 529.

${ }^{21}$ Essa é a tese adotada pela Constituição Federal brasileira, no seu artigo 50, §3०: "Os tratados e convenções internacionais sobre direitos humanos que forem aprovados, em cada Casa do Congresso Nacional, em dois turnos, por três quintos dos votos dos respectivos membros, serão equivalentes às emendas constitucionais." Também art. 50, §40: "O Brasil se submete à jurisdição de Tribunal Penal Internacional a cuja criação tenha manifestado adesão."

22 KELSEN, Hans. Sovereignty. p. 530.
} 
SOUZA, Rubin Assis da Silveira. A irrelevância do conceito de soberania para Hans Kelsen. Revista Eletrônica Direito e Política, Programa de Pós-Graduação Stricto Sensu em Ciência Jurídica da UNIVALI, Itajaí, v.11, n.2, 2ㅇ quadrimestre de 2016. Disponível em: www.univali.br/direitoepolitica - ISSN 1980-7791.

igualmente um sistema normativo superior para que se possa contratar normas externas. Assim, a relação desse Estado signatário com os outros é estabelecida pelo direito internacional, o qual, por sua vez, é tão somente componente desses Estados e não seu fundamento de validade. Na sequência dessa igualdade soberana, conclui-se a formação de uma comunidade internacional.

Há, entretanto, um grave problema nessa perspectiva: se o direito internacional é um componente do sistema legal que o reconhece, então a base de existência de outros Estados em igualdade soberana encontra-se na própria vontade do sistema jurídico que os reconhece, isto é, uma contradição tendo em vista que consequentemente a igualdade soberana limita o próprio conceito de soberania. Para essa configuração a base dos outros sistemas legais é vista como subordinada por aquele sistema legal. Ou seja, o Estado que reconhece internamente a validade do direito internacional e a comunidade internacional não pode ele mesmo reconhecer a soberania dos outros estados no sentido tradicional, o que torna, portanto, problemático o conceito de igualdade soberana não apenas para a concepção de soberania externa ao sistema, mas também para a soberania como sistema normativo interno. Em outros termos, o Estado soberano não poderia efetivamente admitir uma igualdade soberana; caso contrário, ele em si abdicaria da sua situação de sistema jurídico superior, pois dependente do reconhecimento da igualdade soberana dos outros Estados, assim como também não poderia reconhecer essa igualdade soberana nos outros sistemas normativos internos, porque, contraditoriamente, ele mesmo e os outros sistemas normativos internos deixariam de ser soberanos. ${ }^{23}$

${ }^{23}$ KELSEN, Hans. Sovereignty. p. 530. 
SOUZA, Rubin Assis da Silveira. A irrelevância do conceito de soberania para Hans Kelsen. Revista Eletrônica Direito e Política, Programa de Pós-Graduação Stricto Sensu em Ciência Jurídica da UNIVALI, Itajaí, v.11, n.2, 2ㅇ quadrimestre de 2016. Disponível em: www.univali.br/direitoepolitica - ISSN 1980-7791.

Para superar o problema, Kelsen ${ }^{24}$ propõe a divisão da soberania do primado do direito nacional em sentido estrito e em sentido amplo. No primeiro, a ordem interna é composta de acordo com a Constituição e suas normas são postas por atos legislativos, jurisdicionais e administrativos. Em sentido amplo, a ordem jurídica considera, além do sentido estrito, os costumes e tratados internacionais. Levando em consideração o conteúdo do direito internacional, a relação entre dos dois componentes (sentido estrito e amplo) se dá por superordenação e subordinação.

Kelsen ${ }^{25}$ explica a relação afirmando que o Estado que reconhece (superordenação) o direito internacional, submete-se (subordinação), por isso mesmo, ao direito internacional. Assim, a parte que representa o direito nacional em sentido amplo (Constituição e tratados de direito internacional) subordina a parte do Estado em sentido estrito (a Constituição e normas internas). Consequentemente, mesmo a partir do primado do direito estadual, fica comprometido o sentido tradicional de soberania, contudo fica resolvido o problema do reconhecimento dos outros Estados em igualdade soberana, pois tal reconhecimento se dá apenas no seu sentido estrito, não amplo, o que compromete as normas constitucionais, porém não a possibilidade de ratificar tratados. Isso porque o sistema legal do primado Estatal em sentido estrito (Constituição e normas internas), tendo reconhecido o direito internacional, tem como integrante da sua validade esse mesmo direito internacional e, logo, subordina-se a ele quando o mesmo está inserto na própria Constituição. O direito internacional para o primado do sistema normativo estatal, entretanto, não é o sistema normativo

\footnotetext{
${ }^{24}$ KELSEN, Hans. Sovereignty. p. 530 e 531.

${ }^{25}$ KELSEN, Hans. Sovereignty. p. 531.
} 
SOUZA, Rubin Assis da Silveira. A irrelevância do conceito de soberania para Hans Kelsen. Revista Eletrônica Direito e Política, Programa de Pós-Graduação Stricto Sensu em Ciência Jurídica da UNIVALI, Itajaí, v.11, n.2, 2ㅇ quadrimestre de 2016. Disponível em: www.univali.br/direitoepolitica - ISSN 1980-7791.

superior no seu sentido amplo (isto é a Constituição e normas internas somadas à conclusão de tratados internacionais). Isso garante que o Estado submeta-se, e, portanto, abdique da sua soberania em sentido estrito, porém a mantenha em seu sentido amplo. Ocorre, em suma, que após acordada uma norma de direito internacional, o Estado submete-se a ela, porém apenas o Estado pode pactuar ou desfazer os pactos acordados, restando-o um mínimo de soberania.

Conclui-se, portanto, que soberania para o monismo do primado do direito nacional significa que o direito internacional assume sua posição sobre o sistema em sentido exclusivamente estrito (Constitucional e legislação interna), mas não em sentido amplo (Constituição e legislação interna somada à possibilidade de formação de pactos de direito internacional). Ou seja, o direito internacional, mesmo no primado do nacionalismo, assume posição acima da Constituição, mas não acima da possibilidade de reconhecimento do próprio direito internacional como norma válida superior. Aqui, também, abandona-se o conceito de soberania no sentido da impossibilidade de determinação da Constituição por tratados internacionais, pois mesmo a partir da hipótese mais conservadora e nacionalista a soberania, o Estado está invariavelmente comprometido pelos pactos e tratados internacionais, que por tê-los acordado, subordina-se a eles.

\subsection{O PRIMADO DO DIREITO INTERNACIONAL}

Por via oposta, do primado direito internacional, surge a questão de saber como se fundamenta a validade da ordem jurídica nacional. 
SOUZA, Rubin Assis da Silveira. A irrelevância do conceito de soberania para Hans Kelsen. Revista Eletrônica Direito e Política, Programa de Pós-Graduação Stricto Sensu em Ciência Jurídica da UNIVALI, Itajaí, v.11, n.2, 2ㅇ quadrimestre de 2016. Disponível em: www.univali.br/direitoepolitica - ISSN 1980-7791.

Essa validade, afirma Kelsen ${ }^{26}$, tem que ser encontrada a partir da hipótese da validade da ordem jurídica do direito internacional. Isso é possível tão somente a partir do princípio da efetividade, quando se considera que a norma do direito positivo internacional efetivamente determina a base e a esfera de validade dos sistemas jurídicos nacionais. ${ }^{27}$ Portanto, a ordem jurídica internacional determina tanto o fundamento de validade quanto o domínio territorial e o efetivo exercício de poder do Estado. Isso significa que se obtém da esfera internacional a investidura de um indivíduo ou de um grupo para estabelecer e aplicar uma Constituição. Esse mesmo direito internacional valida o grupo perante a comunidade internacional enquanto Estado. Então, a base da validade do direito nacional é fundada sob a condição da eficácia e, logo, está normativamente condicionada. Logo, o direito internacional pode ser interpretado como um sistema legal universal (tão somente universal a partir do

\footnotetext{
${ }^{26}$ KELSEN, Hans. Sovereignty. p. 528.

27 Esclarecendo, tal princípio da efetividade para Kelsen não se refere a um princípio metafísico legalista, como em Hobbes, por exemplo, o qual necessariamente confunde as esferas do ser e do dever-ser. A eficácia corresponde à condição de possibilidade do conhecimento jurídico e não determina a sua validade. Diz o autor: "a eficácia da ordem jurídica como um todo e a eficácia de uma norma jurídica singular são - tal como o ato que estabelece a norma condição de validade. Tal eficácia é condição no sentido de que uma ordem jurídica como um todo e uma norma jurídica singular já não são consideradas como válidas quando cessam de ser eficazes. Mas também a eficácia de uma ordem jurídica não é, tampouco como o fato que a estabelece, fundamento da validade. Fundamento da validade, isto é, a resposta à questão de saber por que devem as normas desta ordem jurídica ser observadas e aplicadas, é a norma fundamental pressuposta segundo a qual devemos agir de harmonia com uma Constituição efetivamente posta, globalmente eficaz, e, portanto, de harmonia com as normas efetivamente postas de conformidade com esta Constituição e globalmente eficazes. A fixação positiva e a eficácia são pela norma fundamental tornadas condição da validade. A eficácia é-o no sentido de que deve acrescer ao ato de fixação para que a ordem jurídica como um todo, e bem assim a norma jurídica singular, não percam a sua validade." KELSEN, Hans. Teoria pura do direito. p. 236. Nesse sentido, o princípio da eficácia no primado do direito internacional refere-se à condição de possibilidade do reconhecimento da validade da ordem jurídica estatal, não a sua própria validade, que tem sua objetividade obtida da pressuposição de uma norma fundamental.
} 
SOUZA, Rubin Assis da Silveira. A irrelevância do conceito de soberania para Hans Kelsen. Revista Eletrônica Direito e Política, Programa de Pós-Graduação Stricto Sensu em Ciência Jurídica da UNIVALI, Itajaí, v.11, n.2, 2ㅇ quadrimestre de 2016. Disponível em: www.univali.br/direitoepolitica - ISSN 1980-7791.

seu aspecto cognitivo e sob o princípio da eficácia) sobre os subsistemas jurídicos nacionais, tornado possível, consequentemente, a coexistências dos sistemas no espaço e na sucessão do tempo.

Assim, para Kelsen ${ }^{28}$, a construção internacionalista exclui o senso original e próprio da expressão soberania. O que é soberano, isto é, o sistema normativo superior, não é o direito nacional, mas a ordem jurídica internacional - esta sim possui o sistema normativo superior. O conceito de soberania nessa hipótese tem de se afastar da noção do primado do direito interno - aqui, soberania significa apenas que o Estado é independente dos outros Estados, assim como a validade dos seus sistemas jurídicos apenas obedece estritamente ao direito internacional e não a outro membro.

O primado do direito internacional, entretanto, não deve ser confundido com a hipótese do Estado mundial. Como visto acima, Kelsen expressamente nega a existência de tal ordem. Portanto, há uma distinção fina, porém extremamente necessária entre a concepção monista do primado do direito internacional e a ideia de um Estado mundial. Para este, deveria haver um órgão centralizado capaz de coagir todos os sistemas a ele subordinados. Nesse aspecto haveria, ainda, a formação de uma administração centralizada detentora do monopólio da força. Para o Estado mundial, então, a validade das normas Constitucionais submeter-se-ia a um estágio superior, do qual obteria a sua objetividade. Essa Constituição mundial alcançaria, dessa forma, sua validade objetiva através da pressuposição de uma norma fundamental mundial. Ao contrário, o primado do direito internacional não requer tal Constituição mundial: não exige uma centralização administrativa e o monopólio da força,

${ }^{28}$ KELSEN, Hans. Sovereignty. p. 529. 
SOUZA, Rubin Assis da Silveira. A irrelevância do conceito de soberania para Hans Kelsen. Revista Eletrônica Direito e Política, Programa de Pós-Graduação Stricto Sensu em Ciência Jurídica da UNIVALI, Itajaí, v.11, n.2, 2ㅇ quadrimestre de 2016. Disponível em: www.univali.br/direitoepolitica - ISSN 1980-7791.

assim como não intervém nos Estados nacionais. Apenas o primado do direito internacional, através do princípio da efetividade, cognitivamente, interpreta externamente uma Constituição nacional como válida, dando a ela status de norma do Estado e pertencente à comunidade internacional. O primado, portanto, apenas reconhece como válido um Estado e exclui os grupos os quais não considera constituintes, sem impor qualquer tipo de coerção a eles, dando-Ihes apenas sentido objetivo da sua legislação interna.

3 A ESCOLHA DE UM OU OUTRO PRIMADO A PARTIR DA CONCEPÇÃO DE VIDA - A IRRELEVÂNCIA CONSTITUCIONAL E JURÍDICA DO CONCEITO DE SOBERANIA

Superada a teoria tradicional do Estado soberano acima do sistema normativo e também superada a teoria dualista, restou apenas o monismo como via possível de se reivindicar a legitimidade do conceito de soberania. Para Kelsen, entretanto, a escolha entre uma ou outra das construções monistas não exerce qualquer influência sobre o conteúdo da ordem jurídica, tanto nacional quanto internacional. ${ }^{29} \mathrm{O}$ Direito internacional sob o primado do sistema jurídico nacional tem o conteúdo idêntico desse mesmo sistema, o qual é havido como ordem jurídica supraordenada das ordens jurídicas estaduais. Mas também o conteúdo do direito nacional permanece idêntico na hipótese do primado do sistema normativo

29 Sobre a tentativa de superação do conceito de soberania e sobre a sua irrelevância jurídica para Kelsen, conferir o recente artigo de Petra GÜMPLOVÁ, Petra: Law, Sovereignty, and Democracy: Hans Kelsen's Critique of Sovereignty. Disponível em: http://www.newschool.edu/uploadedFiles/NSSR/Departments_and_Faculty/Political _Science/Recent_Placements/Gumplova-Law_Sovereignty_Democracy.pdf?n=7291. Acesso em janeiro de 2016. A autora associa a crítica de Kelsen ao conceito de soberania com a sua pretensão de formular uma teoria pura e, especialmente, sobre o seu conceito monista de norma. Ressalta-se, também, que esse projeto kelseniano é fortemente criticado pela autora. 
SOUZA, Rubin Assis da Silveira. A irrelevância do conceito de soberania para Hans Kelsen. Revista Eletrônica Direito e Política, Programa de Pós-Graduação Stricto Sensu em Ciência Jurídica da UNIVALI, Itajaí, v.11, n.2, 2ㅇ quadrimestre de 2016. Disponível em: www.univali.br/direitoepolitica - ISSN 1980-7791.

internacional. Assim, Kelsen ${ }^{30}$ afirma ser um abuso de uma ou outra construção deduzir soluções que poderiam ser tomadas por uma ou outra construção. Um exemplo desse abuso é quando um defensor do primado do direito internacional defende que em caso de conflito normativo o direito internacional tem prevalência, isto é, o conteúdo do direito nacional é nulo. Ocorre que tal conflito de norma nunca pode existir. Uma norma do direito nacional apenas pode ser anulada caso se preveja pelo próprio direito nacional ou pelo direito internacional o processo para sua anulação.

Também Kelsen ${ }^{31}$ expõe o excesso do primado do direito estatal que se funda na pressuposição da soberania do Estado. Assume-se que o direito internacional é válido somente se reconhecido pelo sistema jurídico estatal e se conclui que o Estado não está necessariamente vinculado aos tratados que ratifica. Com isso, sustenta-se que é inconciliável o Estado submeter-se a uma corte internacional com jurisdição obrigatória. Contudo, se o Estado reconhece o direito internacional, então este vale como se vigorasse enquanto ordem jurídica supraestadual. Assim, vale a norma do direito internacional seja qual for o conteúdo das normas pactuadas, ou seja, uma expressiva restrição ao conceito de soberania tão significativo para nacionalistas de todas as espécies.

Ocorre, portanto, que as duas posições limitam o conceito de soberania em seu sentido tradicional (além do sentido tradicional cristão e dualista, no sentido daquele sistema que não se submete a nenhum outro sistema) e ambas as teorias não influenciam no conteúdo tanto do direito Constitucional, quanto no conteúdo do direito internacional.

${ }^{30}$ KELSEN, Hans. Sovereignty. p. 532.

${ }^{31}$ KELSEN, Hans. Sovereignty. p. 533. 
SOUZA, Rubin Assis da Silveira. A irrelevância do conceito de soberania para Hans Kelsen. Revista Eletrônica Direito e Política, Programa de Pós-Graduação Stricto Sensu em Ciência Jurídica da UNIVALI, Itajaí, v.11, n.2, 2ㅇ quadrimestre de 2016. Disponível em: www.univali.br/direitoepolitica - ISSN 1980-7791.

Assim, a discussão acerca da soberania partindo da doutrina tradicional cristã e do dualismo resta superada e a discussão sobre o primado do direito nacional ou o primado do direito internacional é irrelevante para determinar os seus conteúdos. Para Kelsen ${ }^{32}$, a posição das duas teorias monistas pelas quais se alcança a unidade de todo direito vigente tão somente tem paralelo com as concepções de mundo e vida subjetivista e objetivista. O subjetivismo parte da concepção do Eu soberano para compreender o mundo e não pode, desta forma, compreendê-lo como exterior, mas apenas como representação e vontade do Eu. Paralelamente, o primado da ordem jurídica nacional apenas reconhece o mundo externo se tal é parte interna de seu sistema jurídico. Nesse sentido, tal primado pode também ser designado como subjetivismo ou solipsismo de Estado. Por contraste, a concepção objetivista parte do mundo exterior para compreender o Eu. Este Eu, por sua vez, não subsiste como Eu soberano e centro do mundo, mas como parte integrante desse mesmo mundo. Nesse caso, tem-se a construção do primado do direito internacional. Finalmente, Kelsen ${ }^{33}$ afirma que também a cognição permanece intocada pela oposição subjetivismo e objetivismo, assim como permanece intocada a Constituição e os pactos e tratados internacionais atrelados à discussão nacionalismo versus internacionalismo. Ou seja, o estudo da soberania consiste, ao cabo, em um esforço irrelevante para a determinação da constitucionalidade e das relações internacionais.

Enfim, tanto a ciência do direito quanto o controle de constitucionalidade restam independentes do ponto de vista adotado. Mesmo um órgão estatal reivindicando a defesa nacionalista da

\footnotetext{
32 KELSEN, Hans. Sovereignty. p. 534.

33 KELSEN, Hans. Sovereignty. p. 535.
} 
SOUZA, Rubin Assis da Silveira. A irrelevância do conceito de soberania para Hans Kelsen. Revista Eletrônica Direito e Política, Programa de Pós-Graduação Stricto Sensu em Ciência Jurídica da UNIVALI, Itajaí, v.11, n.2, 2ㅇ quadrimestre de 2016. Disponível em: www.univali.br/direitoepolitica - ISSN 1980-7791.

Constituição, o conteúdo dessa normatividade permaneceria idêntica caso o discurso do mesmo órgão ignorasse a ideia de soberania e primado do direito estatal na defesa do primado do direito internacional.

\section{CONSIDERAÇÕES FINAIS}

Algumas conclusões podem ser obtidas acerca da soberania a partir do texto de Kelsen:

A teoria tradicional do direito interno como supremo poder determinante do comportamento humano, em especial a doutrina cristã, mostrou-se logicamente refutada. Para a confirmação da teoria haveria a necessária determinação de um conceito objetivo de soberano ou soberania. Contudo, como visto, tal conceito vincularia esse soberano, o que o torna logicamente impossível.

Também a doutrina dualista se mostra ilógica. Isso porque admitindo a existência simultânea de dois sistemas válidos e independentes ao mesmo tempo, é impossível o reconhecimento de um pelo outro. Quando há tal reconhecimento, a proposta dualista entra em colapso, deixando de ser dualista e tornando-se monista.

Refutada a teoria tradicional e a teoria dualista, resta-nos, para compreender o conceito de soberania, apenas o monismo entre direito nacional e internacional. Para o monismo, há apenas um sistema de normas válidas, o qual pode ser observado a partir do ponto de vista do direito interno, assim como do ponto de vista do direito internacional. Ocorre, entretanto, que para o conteúdo normativo tanto da Constituição quando dos tratados de direito internacional é irrelevante o ponto de vista tomado pelo intérprete. Sendo assim, há de se ratificar a posição de Kelsen quanto à 
SOUZA, Rubin Assis da Silveira. A irrelevância do conceito de soberania para Hans Kelsen. Revista Eletrônica Direito e Política, Programa de Pós-Graduação Stricto Sensu em Ciência Jurídica da UNIVALI, Itajaí, v.11, n.2, 2ㅇ quadrimestre de 2016. Disponível em: www.univali.br/direitoepolitica - ISSN 1980-7791.

desnecessária discussão do tema. Portanto, conclui-se que o tema da soberania pouco importa para a composição do direito internacional, assim como não influencia de forma alguma qualquer espécie de controle de constitucionalidade e torna-se, ao cabo, dispensável para a teoria geral do direito e para a filosofia jurídica.

\section{REFERÊNCIAS DAS FONTES CITADAS}

BRASIL. Constituição da República Federativa do Brasil, de 5 de outubro de 1988.2 Disponível em: http://www.planalto.gov.br/ccivil_03/constituicao/constituicao.htm. Acesso em janeiro de 2016.

DYZENHAUS, David. Kelsen, Heller and Schmitt: Paradigms of Sovereignty Thought. Theoretical Inquiries in Law. Vol 16, n. 2, 2015, p. 337-366.

GÜMPLOVA, Petra. Law, Sovereignty, and Democracy: Hans Kelsen's Critique of Sovereignty . Disponível em: http://www.newschool.edu/uploadedFiles/NSSR/Departments_and_F aculty/Political_Science/Recent_Placements/GumplovaLaw_Sovereignty_Democracy.pdf?n=7291. Acesso em janeiro de 2016.

HART, H.L.A. Kelsen's Doctrine of the Unity of Law. In: PAULSON, Bonnie Litschewski e PAULSON, Stanley (Orgs.). Normativity and Norms: Critical Perspectives on Kelsenian Themes. New York: Oxford University Press Inc.: 2007, p. 553-581.

KELSEN, Hans. Direito internacional e Estado soberano. Tradução de Marcela Varejão. São Paulo: Martins Fontes, 2002.

- Princípios do direito internacional. Tradução de

Ulrich Dressel e Gilmar Antonio Bedin. Ijuí: Editora Unijuí, 2010. 
SOUZA, Rubin Assis da Silveira. A irrelevância do conceito de soberania para Hans Kelsen. Revista Eletrônica Direito e Política, Programa de Pós-Graduação Stricto Sensu em Ciência Jurídica da UNIVALI, Itajaí, v.11, n.2, 2ㅇ quadrimestre de 2016. Disponível em: www.univali.br/direitoepolitica - ISSN 1980-7791.

. Teoria pura do direito. Tradução de João Baptistas Machado. 8. ed. São Paulo: Editora WMF Martins Fontes, 2009.

Sociedad y Naturaleza: una investigacion sociologica. Tradução: Jaime Perriaux. Buenos Aires: Editorial DEPALMA, 1945. - Sovereignty. In: PAULSON, Bonnie Litschewski e PAULSON, Stanley (Orgs.). Normativity and Norms: Critical Perspectives on Kelsenian Themes. New York: Oxford University Press Inc.: 2007, p. 525-536.

VIANELLO, Lorenzo Cordova. Derecho y poder: Kelsen y Schmitt frente a frente. Mexico: Fondo de Cultura Económica, 2010. Edição Kindle.

Submetido em: Março de 2016.

Aprovado em: Junho de 2016. 